\title{
A New Diarylpropane from the Stem Bark of Lindera erythrocarpa Makino ${ }^{\dagger}$
}

\author{
Ryeo Kyeong Ko, Min-Chul Kang, Yeon-Jun Jin, Ho-Min Choi, Bong-Seok Kim, Jong-Heon Han, \\ Gi-Ok Kim, ${ }^{*}$ and Nam Ho Lee ${ }^{\ddagger *}$ \\ Jeju Bio-Industry Development Center, Hi-Tech Industry Development Institute, Jeju 690-121, Korea \\ *E-mail:kimgk350@jejuhidi.or.kr \\ ${ }^{\star}$ Department of Chemistry, Cheju National University, Jeju 690-756, Korea. *E-mail: namho@cheju.ac.kr \\ Received October 1, 2009, Accepted December 23, 2009
}

Key Words: Lindera erythrocarpa, Lauraceae, Diarylpropane, Kanakugiol

Lindera erythrocarpa Makino (Lauraceae) is a deciduous tree widely distributed in Asian countries including China, Japan and Korea. This tree has been utilized as the timber for household furniture in the local communities. Its dried fruits have been used for the alleviation of neuralgia and stomachache as a folk medicine in Japan. ${ }^{1}$ In the previous chemical studies, different type of compounds such as terpenes, ${ }^{2}$ cyclopentenediones ${ }^{3}$ and unsaturated fatty acids. ${ }^{4}$ have been identified from this plant. Recently, the isolated cyclopentenediones, linderone and its derivatives, were reported to have anti-tumor, ${ }^{5}$ anti-fungus $^{6}$ and anti-inflammation ${ }^{7}$ activities. In continuation of our efforts searching for bioactive compounds from plants in Jeju Island, ${ }^{8}$ we became interested in the antioxidative ethanol extract prepared from the stem bark of $L$. erythrocarpa. As a result of phytochemical investigation for this extract, we herein report the isolation of a new compound, 1-(2-hydroxy-3,4,5,6-tetramethoxyphenyl)-1-methoxy-3-phenylpropane (1), named as erythrane. A known compound, kanakugiol (2) was also isolated in this study.
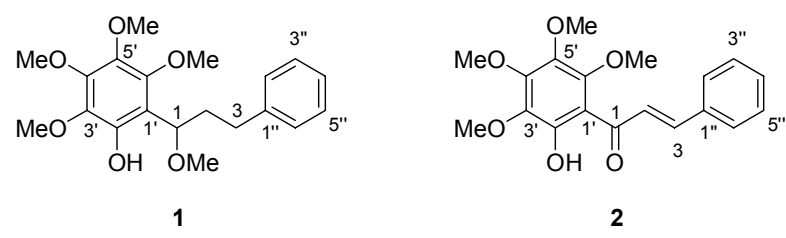

Compound 1 was obtained as a greenish viscous oil. It showed a $[\mathrm{M}+\mathrm{Na}]^{+}$peak at $\mathrm{m} / \mathrm{z} 385.1629(\mathrm{calcd} \mathrm{m} / \mathrm{z} 385.1627)$ in the HR-FABMS, consistent with the molecular formula $\mathrm{C}_{20} \mathrm{H}_{26} \mathrm{O}_{6}$ (eight unsaturations). Examination of ${ }^{13} \mathrm{C}$ and DEPT NMR spectra showed 18 signals accounting for ten aromatic carbons, five methoxy carbons, two methylene carbons and one oxygenbearing methine carbon (Table 1). The presence of aromatic ring(s) were also supported by the UV absorption maxima at 216 and $285 \mathrm{~nm}$. One of the aromatic rings was inferred as phenyl group based on the observation of its typical ${ }^{13} \mathrm{C}$ NMR peaks $(\delta 126.6,129.2,129.4,142.8)$ coupled with ${ }^{1} \mathrm{H}$ NMR signals at $\delta 7.16(1 \mathrm{H}, \mathrm{t}, J=7.5 \mathrm{~Hz}), 7.22(2 \mathrm{H}, \mathrm{d}, J=7.5 \mathrm{~Hz})$ and $7.27(2 \mathrm{H}, \mathrm{t}, J=7.5 \mathrm{~Hz})$. The other aromatic ring was identified as a fully substituted benzene by ${ }^{13} \mathrm{C}$ and DEPT NMR experi-

\footnotetext{
${ }^{\dagger}$ This paper is dedicated to Professor Sunggak Kim on the occasion of his honorable retirement.
}

ments. Besides the above mentioned two aromatic rings, a linear spin chain, $-\mathrm{CH}-\mathrm{CH}_{2}-\mathrm{CH}_{2-}$, was also characterized by ${ }^{1} \mathrm{H},{ }^{13} \mathrm{C}$ and COSY NMR data.

The connection of these subunits was established using HMBC (heteronuclear multiple bond correlations) as well as NOESY NMR experiments (Figure 1). A methoxy group at $\delta_{\mathrm{H}}$ 3.34 is attached to the methine carbon $(\delta 78.9, \mathrm{C}-1)$ in the propyl chain, which was confirmed by their HMBC cross peak. The observation of ${ }^{2} J$ HMBC correlation between H-1 ( $\left.\delta 4.71\right)$ and

Table 1. 1D and 2D NMR data for $\mathbf{1}$ in acetone- $d_{6}$

\begin{tabular}{|c|c|c|c|}
\hline No & $\delta_{\mathrm{C}}(\mathrm{mult})^{a}$ & $\delta_{\mathrm{H}}($ int, mult, $J$ in $\mathrm{Hz}$ ) & $\begin{array}{l}\mathrm{HMBC} \\
(\mathrm{H} \rightarrow \mathrm{C})\end{array}$ \\
\hline 1 & $78.9(\mathrm{~d})$ & $4.71(1 \mathrm{H}, \mathrm{dd}, 8.5,4.5)$ & $\mathrm{C}-2, \mathrm{C}-3, \mathrm{C}-1^{\prime}$ \\
\hline 2 & $37.8(\mathrm{t})$ & $1.98(1 \mathrm{H}, \mathrm{m}), 2.26(1 \mathrm{H}, \mathrm{m})$ & $\mathrm{C}-1, \mathrm{C}-3, \mathrm{C}-1^{\prime}$ \\
\hline 3 & $32.8(\mathrm{t})$ & $\begin{array}{l}2.65(1 \mathrm{H}, \mathrm{ddd}, 15.0,9.0,7.5) \\
2.82(1 \mathrm{H}, \mathrm{ddd}, 15.0,9.5,4.0)\end{array}$ & $\mathrm{C}-1, \mathrm{C}-2$ \\
\hline $1-\mathrm{OCH}_{3}$ & $57.5(q)$ & $3.34(3 \mathrm{H}, \mathrm{s})$ & $\mathrm{C}-1$ \\
\hline $1^{\prime}$ & $115.3(\mathrm{~s})$ & - & \\
\hline $2^{\prime}$ & $146.5(\mathrm{~s})$ & - & \\
\hline $3^{\prime}$ & $138.6(\mathrm{~s})$ & - & \\
\hline $4^{\prime}$ & $140.3(\mathrm{~s})$ & - & \\
\hline $5^{\prime}$ & $148.0(\mathrm{~s})$ & - & \\
\hline $6^{\prime}$ & $148.4(\mathrm{~s})$ & - & \\
\hline 2'-OH & - & $8.8(1 \mathrm{H}, \mathrm{s})$ & C-1', C-2', C-3' \\
\hline $3^{\prime}-\mathrm{OCH}_{3}$ & $61.4(q)$ & $3.78(3 \mathrm{H}, \mathrm{s})$ & C-3' \\
\hline $4^{\prime}-\mathrm{OCH}_{3}$ & $61.4(q)$ & $3.76(3 \mathrm{H}, \mathrm{s})$ & C-4' \\
\hline $5^{\prime}-\mathrm{OCH}_{3}$ & $61.5(\mathrm{q})$ & $3.87(3 \mathrm{H}, \mathrm{s})$ & C-5' \\
\hline $6^{\prime}-\mathrm{OCH}_{3}$ & $61.1(\mathrm{q})$ & $3.72(3 \mathrm{H}, \mathrm{s})$ & C-6' \\
\hline $1 "$ & $142.8(\mathrm{~s})$ & - & \\
\hline $2 " \& 6 "$ & $129.4(\mathrm{~d})$ & $7.22(2 \mathrm{H}, \mathrm{d}, 7.5)$ & \\
\hline $3 " \& 5 "$ & $129.2(\mathrm{~d})$ & $7.27(2 \mathrm{H}, \mathrm{t}, 7.5)$ & $\mathrm{C}-3, \mathrm{C}-1^{\prime \prime}$ \\
\hline $4 "$ & $126.6(d)$ & $7.16(1 \mathrm{H}, \mathrm{t}, 7.5)$ & \\
\hline
\end{tabular}

${ }^{a}$ Determined by DEPT experiments.

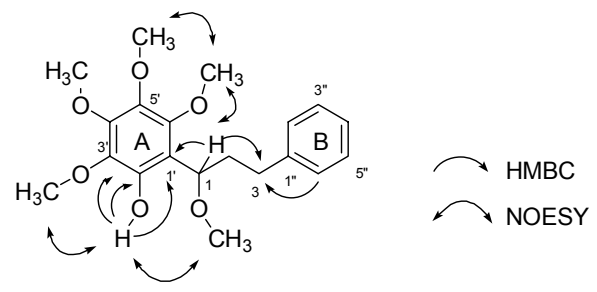

Figure 1. Key HMBC and NOESY correlations in compound $\mathbf{1 .}$ 


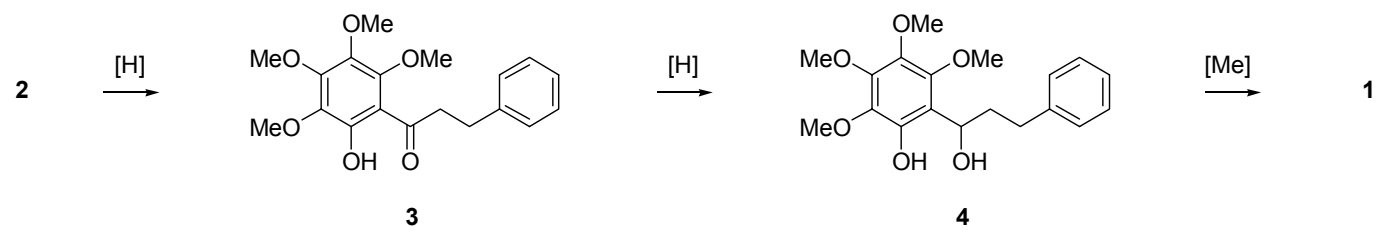

Scheme 1. Proposed biosynthetic pathway to the compound 1 from kanakugiol (2).

C-1' $(\delta 115.3)$ indicated that ring $\mathrm{A}$ is connected to $\mathrm{C}-1$. In the ring $\mathrm{A}$, a hydroxy group was assigned at $\mathrm{C}-2^{\prime}$ as its proton $(\delta$ 8.0) showed ${ }^{2} J$ correlation with $\mathrm{C}-2^{\prime}$ as well as ${ }^{3} J$ correlations with C-1' and C-3' in HMBC spectrum. This hydroxy proton revealed NOESY correlations with protons of methoxy groups attached at C-1 and C-3', which also supports its position at $\mathrm{C}-2^{\prime}$. The other four methoxy groups were all assigned to the remaining positions (C-3', C-4', C-5' and C-6') in the benzene ring A. It was further supported by ${ }^{3} J$ HMBC correlation of methoxy protons with respective aromatic carbons. Finally, the phenyl group was placed to the end of propyl carbon (C-3), which was corroborated by the HMBC cross peak between C-3 $(\delta 32.8)$ and $\mathrm{H}-2 \mathrm{2}(\delta \mathrm{7} .22)$ in ring B. Therefore, compound $\mathbf{1}$ was identified as 1-(2-hydroxy-3,4,5,6-tetramethylphenyl)-1methoxy-3-phenylpropane, named as erythrane.

The compound $\mathbf{1}$ has the same carbon skeleton as found in kanakugiol (2), which was also isolated in this study. The compound $\mathbf{2}$ has previously been isolated from this plant species, ${ }^{9}$ and is assumed to be derived by polyketide biosynthetic pathway. It is interesting to suggest that the compound $\mathbf{1}$ is biosynthetically induced from kanakugiol (2). As shown in Scheme 1, consecutive reductions of the enone 2 to the corresponding alcohol $\mathbf{4}$ followed by methylation step should lead to the formation of compound $\mathbf{1}$.

The antioxidative activities were determined for compounds 1 and 2 using DPPH radicial ${ }^{10}$ and nitric oxide ${ }^{11}$ scavenging methods. For the DPPH radical scavenging test, the compounds 1 and $\mathbf{2}$ showed $\mathrm{SC}_{50}$, the concentration needed to reduce $50 \%$ of DPPH, values of $514.6 \mu \mathrm{g} / \mathrm{mL}$ and $>1000 \mu \mathrm{g} / \mathrm{mL}$ respectively. In this experiment, butylated hydroxyanisole (BHA) was used as a positive control with $\mathrm{SC}_{50}$ of $11.0 \mu \mathrm{g} / \mathrm{mL}$. For the nitric oxide scavenging study, the compounds $\mathbf{1}$ and $\mathbf{2}$ showed $\mathrm{SC}_{50}$ values of $110.3 \mu \mathrm{g} / \mathrm{mL}$ and $333.3 \mu \mathrm{g} / \mathrm{mL}$ respectively, compared to quercetin ( $\mathrm{SC}_{50} 412.4 \mu \mathrm{g} / \mathrm{mL}$ ) used as a positive control in this study. The compound $\mathbf{1}$ showed stronger nitric oxide scavenging activity.

\section{Experimental Section}

Reagents and instruments. All solvents used in this experiment were of analytical grade. Optical rotation was measured on a Jasco P-1030 automatic polarimeter. UV spectra were recorded on a Biochrom Libra S22 spectrophotometer. ${ }^{1} \mathrm{H}$ (500 $\mathrm{MHz})$ and ${ }^{13} \mathrm{C}(125 \mathrm{MHz})$ NMR spectra were recorded in acetone- $d_{6}$ using a Bruker Ultrashield Plus 500 spectrometer, and the chemical shift values were referenced relative to the corresponding residual solvent signals $(\delta 2.04 / 29.9)$. Column chromatography was performed on silica gel $60(0.040-0.063 \mathrm{~mm})$ and RP-C 18 silica gel (230 - 400 mesh) purchased from Merck. Thin layer chromatography (TLC) was performed on silica gel $\mathrm{GF}_{254}$ plates $(0.50 \mathrm{~mm}$, Merck). Butylated hydroxyanisole (BHA), quercetin and 2,2-diphenyl-1-picrylhydrazyl (DPPH) were purchased from Aldrich Co.

Plant material. The whole plant of L. erythrocarpa was collected from Jeju Island in 2004, August. A voucher specimen (06-105) is deposited at Jeju Bio-Industry Development Center, Hi-Tech Industry Development Institute, Jeju, Korea.

Extraction and isolation. The fresh stem bark of L. erythrocarpa Makino was washed and dried by hot blast at $40^{\circ} \mathrm{C}$ for three days. The dried material $(560 \mathrm{~g})$ was pulverized by a mill, and extracted with $70 \%$ aq. ethanol at room temperature under stirring for three days. The extract was filtered to remove the insoluble residue, and the filtrated was concentrated to afford a gummy residue $(68.2 \mathrm{~g})$. The residue was suspended in water, and successively partitioned to give $n$-hexane $(5.0 \mathrm{~g})$, methylene chloride (7.0 g), $n$-butanol (18.4 g) and water (29.6 g) fractions. The methylene chloride fraction $(7.0 \mathrm{~g})$ was subjected to further purification by silica gel column chromatography $(\mathrm{CC})$ with stepwise gradient solvents of $n$-Hexane/EtOAc to afford eight fractions (fr. I-VIII). The fraction I $(557.7 \mathrm{mg})$ was applied to silica gel CC with $n$-Hex/EtOAc (3/1) to give three fractions (fr. I-1 to I-3). Subjection of fr. I-2 to silica gel CC with $\mathrm{CHCl}_{3} /$ $\mathrm{MeOH}(40 / 1)$ provided the compound $2(430.1 \mathrm{mg})$. The compound $1(59.6 \mathrm{mg})$ was separated from the fraction II $(975.4$ mg) by silica gel CC using $n$-Hexane/EtOAc (3/2) as eluents.

1-(2-Hydroxy-3,4,5,6-tetramethylphenyl)-1-methoxy-3-phenylpropane (1). Greenish viscous oil; $\mathrm{UV}\left(\mathrm{CH}_{3} \mathrm{OH}\right) \lambda_{\max } 217$, $285 \mathrm{~nm} ;[\alpha]_{\mathrm{D}}^{25}+4.49^{\circ}$ ( $\left.c 0.025, \mathrm{MeOH}\right) ;{ }^{1} \mathrm{H}$ and ${ }^{13} \mathrm{C}$ NMR data: Table 1; HR-FAB-MS: $m / z 385.1629[\mathrm{M}+\mathrm{Na}]^{+}$(calcd for $\mathrm{C}_{20}$ $\left.\mathrm{H}_{26} \mathrm{O}_{6} \mathrm{Na} 385.1627, \Delta+0.2 \mathrm{mmu}\right)$.

Acknowledgments. This research work was supported by Korean Ministry of Knowledge and Economy through a fund of Regional Industry Technology Development Project (700 01604-2007-01). We appreciates Basic Atomic Energy Research Institute (BAERI), a part of the Nuclear R\&D programs, for the financial support.

\section{References}

1. Liu, S. Y.; Hisada, S.; Inagaki, I. Phytochemistry 1973, 12, 233.

2. Komae, H.; Hayashi, N. Phytochemistry 1972, 11, 853

3. Liu, S. Y.; Hisada, S.; Inaki, I. Phytochemistry 1973, 12, 472.

4. Kim, S. J.; Joh, Y. G. Food Sci. Biotechnol. 2006, 15, 107.

5. Oh, H. M.; Choi, S. K.; Lee, J. M.; Lee, S. K.; Kim, H. Y.; Han, D. C.; Kim, K. M.; Son, K. H.; Kwon, B. M. Bioorg. Med. Chem. 2005, 13, 6182 .

6. Choi, Y. H.; Kwon, S. Y.; Kim, J. H.; Baek, N. I.; Choi, G. J.; 
Cho, K. Y.; Lee, B. M. J. Korean Soc. Agric. Chem. Biotechnol. $\mathbf{2 0 0 3}, 46,150$.

7. Wang, S. Y.; Lan, X. Y.; Xiao, J. H.; Yang, J. C.; Kao, Y. T.; Chang, S. T. Phytotherpy Res. 2008, 22, 213.

8. (a) Sultana, N.; Lee, N. H. Phytotherapy Res. 2007, 21, 1171. (b) Kim, J. M.; Ko, R. K.; Hyun, J. W.; Lee, N. H. Bull. Korean Chem. Soc. 2009, 30, 261. (c) Ko, R. K.; Lee, S.; Hyun, C. G.; Lee, N. H. Bull. Korean Chem. Soc. 2009, 30, 1376. (d) Sultana,
N.; Lee, N. H. Bull. Korean Chem. Soc. 2009, 30, 1729.

9. (a) Leong, Y.-W.; Harrison, L. J.; Bennett, G. J.; Kadir, A. A.; Connolly, J. D. Phytochemistry 1998, 47, 891. (b) Lee, S. M.; Baek, S. H.; Lee, C. H.; Lee, H. B.; Kho, Y. K. Natural Product Sciences 2002, 8, 100.

10. Blois, M. S. Nature 1958, 29, 1199.

11. Shukla, S.; Mehta, A.; Bajpai, V. K.; Shukla, S. Food Chem. Toxicol. 2009, 47, 2338. 